\title{
ENTRE A SOBERANIA DA LEI E O CHÃO DA PRISÃO: A MATERNIDADE ENCARCERADA
}

\author{
Ana Gabriela Mendes Braga
}

BETWEEN THE SOVEREIGNTY OF THE LAW AND THE FLOOR OF THE PRISON: INCARCERATED MATERNITY

\section{RESUMO}

A CRIMINOSA E A MÃE OCUPAM LUGARES OPOSTOS NO REPERTÓRIO DE PAPÉIS DESIGNADOS ÀS MULHERES NA NOSSA SOCIEDADE. A PARTIR DE CINCO MICRONARRATIVAS DE MULHERES ENCARCERADAS NO BRASIL, PRETENDESE PROBLEMATIZAR O EXERCÍCIO DA MATERNIDADE NA PRISÃO E O LUGAR DA “MĀE CRIMINOSA" NO SISTEMA DE JUSTIÇA. AS ESTÓRIAS AQUI NARRADAS SĀO FRUTOS DA PESQUISA "DAR À LUZ NA SOMBRA", QUE TEVE COMO OBJETIVO IDENTIFICAR NECESSIDADES E ENTRAVES PARA O EXERCÍCIO DOS DIREITOS MATERNOS DE MULHERES EM SITUAÇÃO DE PRISÃo. PARA TANTO, FOI UTILIZADA A PESQUISA EMPÍRICA DE ABORDAGEM QUALITATIVA, COM COMBINAÇÃO DAS TÉCNICAS DE ENTREVISTAS, GRUPO FOCAL, VISITA IN LOCO, SOMADAS À PESQUISA LEGISLATIVA E BIBLIOGRÁFICA. AO FINAL, SERĀO DISCUTIDAS AS ESTRATÉGIAS, PROBLEMÁTICAS E CONSEQUÊNCIAS QUE ENVOLVEM A DEFESA DE DIREITO DAS MULHERES E A LUTA DO MOVIMENTO FEMINISTA EM RELAÇÃO AO SISTEMA DE JUSTIÇA CRIMINAL. POR FIM, SERÃO ELENCADAS ALGUMAS PAUTAS IMPORTANTES DE PESQUISA PARA A CONTINUIDADE DO PRESENTE DEBATE.

\section{PALAVRAS-CHAVE}

GÊNERO; PRISÃO; MATERNIDADE; MÃE CRIMINOSA; NARRATIVAS.

\section{ABSTRACT}

THE CRIMINAL AND THE MOTHER OCCUPY OPPOSITE PLACES IN THE REPERTORY OF PAPERS ASSIGNED TO WOMEN IN OUR SOCIETY. FROM FIVE MICRONARRATIVES OF WOMEN INCARCERATED IN BRAZIL, THIS PAPER AIMS TO DISCUSS THE EXERCISE OF MATERNITY IN THE PRISON AND THE PLACE OF "CRIMINAL MOTHERS" IN THE JUSTICE SYSTEM. THESE STORIES HAVE BEEN COLLECTED DURING THE RESEARCH "GIVING BIRTH ON PRISON", WHICH AIMED TO IDENTIFY NEEDS AND OBSTACLES TO ENSURE THE RIGHTS OF INCARCERATED WOMEN. THIS RESEARCH USED AN EMPIRICAL METHOD BASED ON A QUALITATIVE APPROACH THAT COMBINES THE REALIZATION OF INTERVIEWS AND FOCUS GROUP WITH SOME VISITS "IN LOCUS", COMPLEMENTED BY LEGISLATIVE AND BIBLIOGRAPHICAL RESEARCH. THIS PAPER PROPOSES A REFLECTION BEYOND THE ORIGINAL ANALYSIS. IT DISCUSSES THE STRATEGIES, THE PROBLEMS AND THE CONSEQUENCES INVOLVED IN THE DEFENSE OF WOMEN'S RIGHTS IN RELATION TO THE CRIMINAL JUSTICE SYSTEM UNDER A FEMINIST PERSPECTIVE. BESIDES THAT, THIS PAPER WILL PROPOSE SOME IMPORTANT RESEARCH LINES THAT COULD HELP THE EVOLUTION OF THIS DEBATE.

\section{KEYWORDS}

GENDER; PRISON; MATERNITY; CRIMINAL MOTHER; NARRATIVES. 


\section{INTRODUÇÃO}

Esta é a estória.

(Guimarães Rosa)

A frase acima, que abre o conto “As margens da alegria”, de Guimarães Rosa (2001, p. 49), traduz a proposta deste artigo: provocar algumas reflexões acerca da maternidade e do cárcere no Brasil a partir de quatro micronarrativas de mulheres encarceradas. São pequenas estórias, relatos, lampejos, insights, choros; singulares, doloridos, sintéticos, socos no estômago, às margens da alegria, narrados com o objetivo de dar visibilidade a essas mulheres, presença aos corpos calados, e despertar diferentes sensibilidades em relação à temática do encarceramento. Suas estórias têm pouco espaço nas salas de audiência, levantamentos estatísticos, elaboração de políticas públicas, e até mesmo na produção científica. No entanto, são essas vidas que dizem do encarceramento feminino e, mais, falam do que é ser mulher, mãe e - em grande maioria - pobre e negra no sistema prisional brasileiro do presente.

Pesquisar o sistema de justiça criminal, pensar a polícia, a justiça e a prisão, é ser colocada cara a cara com questões de gênero, raça e pobreza. Uma visita às unidades prisionais ou uma olhada nas estatísticas da população prisional logo nos mostram quem está presa no Brasil: a população pobre e negra, com um crescente aumento da representatividade das mulheres nesse universo. De acordo com dados do Departamento Penitenciário Nacional (DEPEN) ${ }^{1}$, nossas presas são em sua maioria jovens, pretas ou pardas, de baixa renda, baixa escolaridade, acusadas ou condenadas por crimes relacionados às drogas, e mães.

O crescimento do encarceramento feminino é um fenômeno que tem se acentuado nesse começo de século. Apesar de as mulheres ainda serem minoria no sistema prisional, entre 2000 e 2012, a população carcerária masculina brasileira aumentou $130 \%$, enquanto a feminina cresceu 246\%. Nos anos 2000, a população de mulheres era de 10.112, já em 2012 esse número passou para mais de 35 mil, representando $6,4 \%$ da população prisional do país em um universo de 548.003 pessoas presas. $^{2}$ Apenas a título de comparação, a população brasileira cresceu cerca de $12 \%$ no mesmo período, no ano 2000 eram 169.590.693 brasileiros, e dez anos depois 190.755.799. ${ }^{3}$ De acordo com os últimos dados coletados pelo DEPEN, ${ }^{4}$ em junho de 2014 a população prisional brasileira chegou a 607.731 pessoas, das quais 37.380 eram mulheres, sendo $63 \%$ delas presas por crimes relacionado ao comércio ilegal de drogas.

Com o aumento do encarceramento feminino e a intensificação das lutas por igualdade entre gêneros, a temática de gênero e prisão tem ganhado fôlego nos últimos anos, trazendo maior visibilidade para a população prisional feminina - e, mais recentemente, também para a comunidade LGBT nos cárceres. Novas pautas ocupam 
a agenda pública, quebrando o silenciamento em torno de "temas tabus", exigindo reconhecimento de identidades, assim como de direitos sexuais e reprodutivos. Temas como maternidade e prisão, visita íntima homoafetiva e alas especiais para as mulheres trans nos estabelecimentos masculinos são pautas importantes do atual debate político-penitenciário. Contudo, como se problematizará neste artigo, essa mesma visibilidade pode trazer outras amarras, e, assim, criar paradoxos na luta pela defesa dos direitos das mulheres e da população LGBT.

Os discursos e as práticas de reconhecimento de direitos e especificidades de gêneros trazem consigo o efeito perverso de, ao definir subjetividades e legitimidades, selecionar e conformar as pessoas em sujeitos de direitos, sujeitando-as aos padrões de normalidade e moralidade do fazer jurídico. Para Carol Smart (1989, p. 162), "in order to claim rights the individual must fit into the specified categories", ${ }_{5}^{5}$ ou, nas palavras de Judith Butler (2003, p. 233), ao problematizar o reconhecimento do casamento gay, "quem pode desejar o Estado, quem pode desejar o desejo do Estado".

O Estado, ao desejar, constitui subjetividades - desejáveis e desejantes. Que mulher pode ser mãe? Alguma pode não ser? Quem pode optar por interromper a gravidez? Como ser mãe? Defina família desestruturada. Toda mulher merece proteção em sua dignidade sexual? Onde colocar as / os trans? Alguém perguntou para elas? Quem são elas? Essas são questões que o sistema de justiça responde a partir da racionalidade que lhe é própria, fundante das categorias jurídicas, que atendem a uma lógica binária e heteronormativa, de modo a constituir gêneros e fixar desejos a partir de uma ordenação normalizante, biologicista e heterossexual.

O sistema de justiça é atravessado por marcadores de gênero, e o exercício dos direitos individuais ocorre nesse mesmo cenário. Ainda quando a demanda de reconhecimento de direito das mulheres é atendida, o acesso à justiça segue seletivo e perverso. Primeiro porque só algumas pessoas, sob certas condições, terão efetivo acesso à justiça, e ainda assim um acesso precário e limitado; e depois porque o reconhecimento por um sistema sexista e androcêntrico (que constrói hierarquias a partir dos sexos, privilegiando os homens e a perspectiva masculina) pode perverter a autonomia e o exercício de liberdade individual - princípios que norteiam a luta feminista no campo social:

we cannot predict the outcome of any individual law reform. Indeed the main dilemma for any feminist engagement with law is the certain knowledge that, once enacted, legislation is in the hands of individuals and agencies far removed from the values and politics of the women $\mathrm{s}$ movement. ${ }^{6}$ (SMART, 1989, p. 164).

Os avanços legais em termos de reconhecimento de outras sujeitas de direito esbarram em personagens e instituições do sistema de justiça com padrões de gênero 
arraigados, os quais servirão de base para a leitura do mundo social e a interpretação do direito. De acordo com a lição de Carol Smart (1989, p. 164) "[...] law may have quite different effects depending on who is the subject of the law". 7

No sentido dessa reflexão é que se propõe desconfiar do direito, da normalidade, da governança, e questionar-se que subjetividades essas práticas estão produzindo, buscando seguir a proposta de Debora Diniz em relação à construção da perspectiva feminista em pesquisa:

Uma pesquisa feminista parte do acaso da matéria, reconhece a sexagem como um gesto inaugural do regime político do gênero, investiga a moral patriarcal na vida e sobrevida das mulheres, desconfia das instituições que movem a governança das mulheres no asilo, na esquina, no convento ou na prisão. (DINIZ, 2014, p. 19).

As estórias aqui narradas foram ouvidas na prisão durante pesquisa denominada Dar à luz na sombra: condições atuais e possibilidades futuras para o exercício da maternidade por mulheres em situação de prisão, realizada ${ }^{8}$ no âmbito do Projeto Pensando o Direito - uma parceria entre a Secretaria de Assuntos Legislativos do Ministério da Justiça (SAL/MJ) e o Instituto de Pesquisa Econômica Aplicada (Ipea).

A pesquisa teve como objetivo identificar necessidades e entraves para o exercício dos direitos maternos de mulheres em situação de prisão e elaborar propostas de políticas públicas, com ênfase em alterações legislativas que promovam o exercício da maternidade dessas mulheres. Para tanto, foi utilizada a pesquisa empírica de abordagem qualitativa, combinando técnicas de entrevistas, grupo focal, visita in loco, somadas à pesquisa legislativa e bibliográfica. De agosto de 2013 a abril de 2014 realizamos cinquenta entrevistas com personagens do sistema de justiça, conversas informais com mais de oitenta presas e visitas a estabelecimentos prisionais, creches e unidades materno-infantis em seis estados brasileiros (Minas Gerais, Paraná, Ceará, Bahia, São Paulo, Rio de Janeiro) e na Argentina. As entrevistas foram gravadas, e a partir das visitas e das conversas informais produziram-se relatórios dos estados visitados. A partir das diversas vozes do campo, realizou-se a análise em torno das condições atuais do encarceramento feminino no Brasil e das possibilidades futuras no tocante ao exercício da maternidade pelas mulheres presas. Ao final, foi desenhado um retrato das atuais condições dessas mulheres e a percepção de diversas personagens envolvidas na temática e elaboradas trinta propostas, entre alterações legislativas, políticas públicas e políticas criminais, com foco principal no desencarceramento.

A proposta deste artigo vai além da pesquisa que o originou, primeiro no que diz respeito à originalidade do recorte: uma seleção de estórias que sintetizam questões centrais do campo de pesquisa, que não o esgotam, mas são significativas da realidade observada. E depois porque o presente texto pretende aprofundar as reflexões acerca 
dos papéis sociais de mãe e criminosa, tema que foi tratado apenas subsidiariamente no relatório da referida pesquisa (BRASIL, 2015).

Cabe ressaltar que, apesar da temática ser atravessada pela interseccionalidade, a abordagem proposta aqui não abrange os recortes de raça ou socioeconômico, tampouco pretende aprofundar a relação entre os três marcadores sociais em debate (raça, gênero e pobreza) - ainda que essas chaves pudessem dizer muita coisa acerca das maternidades encarceradas. Segundo Smart, somente com a segunda onda do feminismo surgiram novas vozes, trazendo questões raciais e de diferenças étnicas, as quais não poderiam ser meramente acrescentadas aos já existentes quadros conceituais - seria necessário repensar o mundo social (SMART, 1989, p. 2). Certamente pesquisas específicas nesse recorte merecem ser produzidas, e, em respeito aos outros mundos sociais, o tema não será desenvolvido nesta reflexão, a qual se concentrará na chave gênero-maternidade-prisão.

De início, serão abordadas as categorias de mãe e criminosa como capturas do gênero feminino e como a sobreposição dessas duas categorias conforma a maternidade encarcerada. Em seguida, serão analisadas algumas conquistas legais e as consequências desse reconhecimento para a produção de subjetividades pelo sistema de justiça. Após essas reflexões, serão apresentadas cinco estórias ouvidas no campo de pesquisa, a partir das quais se pretende problematizar o exercício da maternidade na prisão e o lugar da "mãe criminosa" no sistema de justiça. Ao final, serão discutidas as estratégias, problemáticas e consequências que envolvem a defesa de direito das mulheres, bem como a luta do movimento feminista ${ }^{9}$ em relação ao sistema de justiça criminal, e, ainda, elencadas algumas pautas importantes de pesquisa para a continuidade do presente debate.

\section{Mãe e Criminosa: DUAS CAPTURAS DO GÊNERO FEMINinO}

Um dos pontos-chave da análise criminológica apontados pela pesquisa, ${ }^{10}$ e que ganha destaque neste artigo, são as formas e consequências das representações de gênero nas práticas e discursos do sistema de justiça. A mulher presa transita entre os papéis de mãe e criminosa, papéis estes que ocupam posições diametralmente opostas na representação do feminino: o primeiro pautado pela maternidade como vocação natural, exclusiva e sacralizada da mulher; e o segundo marcado pelo crime como um desvio das expectativas sociais e morais que recaem sobre quem nasce sob o sexo feminino.

Para Carol Smart (1976, p. 143), o tradicional papel e status da mulher é reconfirmado pelas instituições penais: "This rationale is based on the assumption that the woman who acepts her tradicional role, who is passive, gentle and caring, is also noncriminal”. ${ }^{11} \mathrm{O}$ papel tradicionalmente designado à mulher é a maternidade, cujas exigências e performances são representadas como irreconciliáveis com a vida no crime - 
ainda que perversamente se aceite conciliá-lo com a vida na prisão. O entrelaçamento dos universos da prisão e da maternidade produz um exercício da maternidade no registro do sacrifício e da disciplina, atendendo ao projeto mais amplo de domesticar o desvio e o desejo feminino, criminal e sexual. A casa e a cria são trazidas para dentro do cárcere, vigiadas, ensinadas, disciplinadas a partir de parâmetros restritos de normalidade de gênero e família.

Para a análise do emaranhado de ações e afirmações que produzem a mãe criminosa no espaço prisional, se recorrerá ao conceito de dispositivo, presente na história da sexualidade de Michel Foucault. O autor demarca o conceito a partir de três lugares:

[...] em primeiro lugar, um conjunto decididamente heterogêneo que engloba discursos, instituições, organizações arquitetônicas, decisões regulamentares, leis, medidas administrativas, enunciados científicos, proposições filosóficas, morais, filantrópicas. Em suma, o dito e o não dito são os elementos do dispositivo. O dispositivo é a rede que se pode tecer entre estes elementos.

Em segundo lugar, gostaria de demarcar a natureza da relação que pode existir entre estes elementos heterogêneos. [...] entre estes elementos, discursivos ou não, existe um tipo de jogo, ou seja, mudanças de posição, modificações de funções, que também podem ser muito diferentes.

Em terceiro lugar, entendo dispositivo como um tipo de formação que, em um determinado momento histórico, teve como função principal responder a uma urgência. $\mathrm{O}$ dispositivo tem, portanto, uma função estratégica dominante. (FOUCAULT, 2000, p. 244 et seq.).

A partir do conceito desenvolvido por Foucault, propõe-se pensar o campo da maternidade encarcerada em termos de um dispositivo - como um emaranhado de práticas e discursos que disputam as definições da mãe criminosa e visam responder às chamadas demandas de gênero em relação ao sistema de justiça criminal. Logo, na presente análise, propõe-se delinear o dispositivo da maternidade encarcerada como: i) formado pelas diversas formas (sentenças, organizações espaciais, regras, arranjos, saberes) que constituem a mulher mãe no sistema de justiça criminal; ii) cujas definições estão em constante disputa pelas personagens e instituições envolvidas; iii) e que atende a demanda de reconhecimento das mulheres, ao mesmo tempo que naturaliza e fixa posições de gênero.

A ação desse dispositivo permite que uma mesma medida ao garantir direitos produza violações; ou ainda que, sob o discurso de reconhecimento das diferenças, 
imponham-se desigualdades, limitando-se ainda mais as formas da mulher estar no mundo. Na visão de Gilles Deleuze, o dispositivo:

é uma espécie de novelo ou meada, um conjunto multilinear. É composto por linhas de natureza diferente e essas linhas do dispositivo não abarcam nem delimitam sistemas homogêneos por sua própria conta (o objeto, o sujeito, a linguagem), mas seguem direções diferentes, formam processos sempre em desequilíbrio, e essas linhas tanto se aproximam como se afastam uma das outras. Cada linha está quebrada e submetida a variações de direção (bifurcada, enforquilhada), submetida a derivações. Os objetos visíveis, as enunciações formuláveis, as forças em exercício, os sujeitos numa determinada posição, são como que vetores ou tensores.

(DELEUZE, 1990, p. 155).

A representação criminosa, que se sobrepõe às outras, funciona como um vetor que aponta à mulher um certo destino. A subjetividade da presa é reduzida ao seu crime e o interrogatório é seu único momento de fala "na Justiça", uma fala pautada, engasgada, limitada ao que lhe foi perguntado, se lhe for perguntado. No campo da pesquisa, foi comum a percepção de ausência de lugares de escuta da mulher acerca de seus desejos e suas possibilidades. A categoria "criminosa" basta para deslegitimar a presa como boa mãe, logo, o sistema de justiça, ao blindar muitas das possibilidades de exercício da maternidade por mulheres processadas ou condenadas, não leva em conta o contexto específico daquela mulher, tampouco a existência de formas de família e organizações de gêneros distintas da tradicional família nuclear, biparental e heterossexual.

A anormalidade da mulher criminosa remete aos ecos do positivismo criminológico, ainda hoje presente nas representações das criminosas. Lombroso e Ferrero (2004, p. 183) enunciam a dupla excepcionalidade da mulher delinquente: enquanto criminosa ela é excepcional em relação à sociedade não criminosa (civilized people), e enquanto mulher é excepcional frente ao número total de criminosos, "e como uma dupla exceção a mulher criminosa é um verdadeiro monstro".

Nesse enunciado, as provas da degeneração feminina (que levariam a mulher ao desvio: seja pelo crime, seja pela prostituição) aparecem diretamente relacionadas à construção do gênero feminino; seriam elas: falta de afeição maternal, presença de qualidades masculinas, sexualidade exagerada, preocupação com os próprios desejos. Ao dirigir sua energia para a satisfação sexual, a "degenerada" se desvia do padrão de normalidade, que impunha a maternidade como pauta exclusiva da sexualidade feminina (LOMBROSO; FERRERO, 2004, p. 185).

Contudo, essas representações não estão dadas, solidificadas, ao contrário, elas estão em constante disputa no campo do direito. Essas categorias são agenciadas pelas 
atrizes e atores do sistema de justiça, inclusive pelas presas em suas práticas e discursos. O excesso legal do discurso jurídico, desejante de normalizar as mulheres, produz representações em torno do que é ser mãe geralmente associadas ao sacrifício e à abdicação. No campo ouvimos diversos discursos que colocavam em xeque a maternidade da mulher presa, como na fala da diretora do Centro de Referência à Gestante Privada de Liberdade em Minas Gerais, para a qual as mulheres costumam "usar o filho para ter um lugar melhor na prisão", ou ainda de acordo com a diretora da Unidade Materno Infantil do Rio de Janeiro, que as acusa "de preferirem o cigarro, a droga, aos filhos". Apesar de geralmente possuírem estruturas melhores em relação ao restante da prisão e de certamente a gravidez ser uma real possibilidade de ter acesso a mais direitos no espaço prisional, na maioria das alas materno-infantis é proibido o uso de cigarro em qualquer espaço (e muito mais difícil o acesso às drogas ilegais). O desejo e a abstinência (com ofertas de tratamento reduzidíssimas) dessas mulheres colocam em xeque sua capacidade e amor pela maternagem, a qual opera geralmente na chave do sacrifício, nunca do gozo.

O sistema de justiça criminal atua sobre as mulheres querendo a reforma não só de sua alma, mas que elas exerçam com normalidade a representação de papéis de gênero, produzindo, organizando, fixando os valores atribuídos ao feminino e as consequentes desigualdades advindas desse marco. Nesse cenário, a maternidade é peça-chave nos discursos de salvação feminina, como o caminho que leva a "mulher desviante" de volta ao seu rumo, a reaproxima de seu destino, de sua missão originária, da "verdadeira natureza feminina", de seu devir mãe. Por isso, esse caminho é vigiado, regrado, disciplinado, e a maternidade pode funcionar como incremento punitivo para a mulher encarcerada. O poder normativo atua sobre a mulher, bebês e crianças, para além do jurídico, justamente no que excede o regime da lei - ou seja, nas capilaridades, pequenas práticas cotidianas, que conformam o poder penitenciário, que, antes de ser um projeto ou uma ciência, é "uma técnica que se aprende, se transmite, e que obedece a normas gerais" (FOUCAULT, 2002, p. 245) -, no sentido de normalizar, a partir do controle e da vigilância, qualquer indivíduo que mantenha um comportamento alijado dos padrões de normalidade e moralidade estabelecidos.

\section{ENTRE A SOBERANiA DA LEI E O CHÃO DA PRISÃO: A MATERNIDADE ENCARCERADA}

Em 1957 a Assembleia Geral da ONU aprovou as Regras Mínimas para o Tratamento do Preso, com princípios e orientações de organização institucional e prática penitenciária. As mulheres e jovens privadas de liberdade tiveram que esperar mais de cinquenta anos para terem seus direitos e especificidades reconhecidos pela legislação internacional, com a aprovação em 2010, pela mesma Assembleia, das Regras para o Tratamento das 
Mulheres Presas (Regras de Bangkok). A regra n. 1 de Bangkok determina atenção às necessidades específicas das mulheres a fim de alcançar a substancial igualdade de gênero, de materializar o princípio da não discriminação, este previsto na regra n. 6 das Regras Mínimas para o Tratamento do Preso.

Do ponto de vista simbólico, a aprovação das regras foi um importante passo na garantia de direitos. Contudo, ainda que o Estado brasileiro - membro da ONU - deva respeito às regras, não há sanção por não cumpri-las. A violação de todos os tipos de direitos segue sendo a regra nas nossas prisões, e seus números e histórias ficam trancados atrás das grades. Segundo Heidi Cerneka:

[...] há uma escassez total de informação sobre as regras de Bangkok e poucos estudos sobre as mulheres encarceradas. Mesmo que isso tenha melhorado nos últimos anos, ainda faltam dados concretos e sérios sobre este assunto, para garantir que políticas públicas nacionais e internacionais correspondam à realidade e às necessidades da mulher. As Regras 67-70 apontam a falta de informação desse assunto e a necessidade de fomentar investigações, estudos e divulgação sobre a realidade e das causas das mulheres em conflito com a lei. (CERNEKA, 2012, p. 18).

Da mesma forma, do ponto de vista da legislação nacional, pode-se dizer que houve um considerável avanço na última década. A Lei n. 11.942/09 deu nova redação aos artigos 14, § 3º 83 e 89 da Lei de Execução Penal (Lei n. 7.210/84) para assegurar às mães presas, aos recém-nascidos e às crianças condições mínimas de assistência. A Lei n. 12.203/12, que reformou a matéria de medidas cautelares, inseriu no artigo 318 do Código de Processo Penal a previsão de substituição da prisão preventiva pela prisão domiciliar nos casos de gestante a partir do sétimo mês de gravidez, ou sendo esta de alto risco, e de pessoa imprescindível aos cuidados especiais de pessoa menor de 6 anos de idade ou com deficiência. Mais recentemente, a promulgação da chamada Lei de Convivência Familiar (Lei n. 12.962/14) alterou o Estatuto da Criança e Adolescente (ECA) para facilitar a convivência da criança e do adolescente com seu pai ou mãe presa.

Longe da soberania da lei, o chão da prisão é feito de violações de direitos, que caracterizam o passado e o presente do sistema prisional brasileiro e se acentuam em relação às mulheres encarceradas. Há um déficit histórico em relação ao planejamento e à execução de políticas públicas voltadas ao coletivo feminino nas prisões, uma vez que a maioria das políticas penitenciárias (cuidados com a saúde, regime de visita, manutenção de vínculos, arquitetura prisional) foi pensada para a população masculina, tradicionalmente majoritária nos estabelecimentos prisionais. Por conta disso, ainda hoje, milhares de mulheres vivem gestações, partos e maternidades precárias, e suas crianças formam parcela invisível da população prisional - contrariando 
a Regra de Tóquio n. 3, que determina que sejam registrados número e informações pessoais das crianças que ingressam nas prisões com a mãe.

Contudo, cabe problematizar em que medida esses avanços refletiram em ganhos concretos para as mulheres processadas e condenadas no Brasil. Primeiro porque quando há uma política específica para a gestante ou puérpera ela só atinge parte das mulheres, principalmente as que estão nas unidades perto das capitais. Segundo porque mesmo quando eficiente, a garantia de direitos por parte do Estado gera uma punição extra, sutil: mais uma esfera da vida disciplinada, mais uma vida normalizada, micropoderes que conformam as estórias que se seguirão. E, por último, a defesa de mais direitos pode gerar o efeito colateral de reforçar a escolha pelo encarceramento.

A construção de um aparato de berçário e creche nas prisões tem motivado recusas de prisão domiciliares sob o argumento de que a mãe e o bebê estariam melhor ali do que na rua. De acordo com Gina Pontes Moura, defensora pública do estado do Ceará entrevistada na pesquisa, o juiz lida com a prisão como uma política social: "Se for minimamente organizada a unidade, o juiz acha melhor a prisão que a rua, por considerar haver menos suporte do lado de fora". Para a defensora, "a existência de creche tem justificado a manutenção da prisão provisória, infelizmente. A política está errada - não é investir em creche para manter a provisória, mas investir na liberdade em detrimento da prisão provisória”. Ou seja, à medida que se melhoram as prisões, paradoxalmente prendem-se mais mulheres e crianças, sob o discurso benevolente e paternalista de que a vida atrás das grades é o melhor destino para ambas. Nesse sentido, “[...] não seria exagerado afirmar que há entre nós um discurso domesticado para ver um sujeito-vítima, espectador da sua condição, deixando para segundo plano o sujeito-agente” (RIFIOTIS, 2007, p. 234).

O reconhecimento de direitos pelo sistema de justiça não significa a conquista da mulher enquanto atriz política nesse cenário: sujeita-agente. Pelo contrário, ao ser provocado, o sistema responde fixando a mulher como sujeita-vítima, menosprezando sua agência, seu poder, sua autonomia, pervertendo sutilmente os ideais de emancipação e empoderamento que motivaram a luta feminista por reconhecimento de direitos.

Ciente das consequências e limites da defesa de políticas não dissociadas do encarceramento e do sistema de justiça criminal, é importante pautar o marco político e a conclusão-chave da pesquisa: o melhor exercício de maternidade é sempre em liberdade. Por isso, para se falar em exercício de direito dessas mulheres, há de se falar em uma mudança nos rumos da política criminal, principalmente, por meio da reforma da Lei de Drogas (mais da metade das mulheres brasileiras estão presas por crime relacionado às drogas) e da aplicação das garantias da legislação já existente, visando o não encarceramento dessas mulheres e crianças.

O encarceramento feminino impacta de forma brutal a família da presa, na medida em que ela não só afeta a mulher, mas todo o seu entorno. Na nossa sociedade, a responsabilidade pela administração doméstica e o cuidado com filhos e filhas são 
atribuídos, em regra, à mulher. A naturalização do cuidado como uma tarefa tipicamente feminina reforça o estereótipo de gênero e pauta a organização familiar de muitas brasileiras, dentro e fora das prisões. E, uma vez que são elas, em geral, as responsáveis pelos cuidados com a casa, com as filhas e filhos, a prisão dessas mulheres impacta de forma imediata, e muitas vezes definitiva, a vida familiar. Essa reflexão provoca outro desafio para a luta pela igualdade de gênero: deslocar a problemática do cuidado do âmbito feminino. A discussão proposta em termos de maternidade e prisão fica concentrada nas mulheres presas e no espaço prisional feminino, somando-se às vozes que naturalizam o lugar da mulher no cuidado familiar e doméstico e silenciando novas possibilidades em torno das relações de paternidade, cuidado e prisão.

Como narrado acima, recentes conquistas legais garantiram, no plano formal, direitos às mulheres encarceradas. Nesse ponto, uma das amarras do encontro entre gênero e direito, ao mesmo tempo que reconhece a mulher em suas peculiaridades, o faz desde um cenário do patriarcado, reafirmando o seu lugar social. Esse é o limite das conquistas, que, ao não subverterem a ordem de gênero, reafirmam papéis sociais apropriados. Um horizonte subversivo, do ponto de vista da desnaturalização dos papeis de gênero, será pensar em creche nas unidades masculinas ou prisão domiciliar para o pai preso.

Outra importante conclusão da pesquisa, fundamental para as leituras das estórias que se seguem, é que não há uma solução única. A prepotência do direito de encaixar pessoas em categorias e relações em formas rígidas se mostra falha perante a diversidade e complexidade individual e social. A escolha do que fazer em relação à maternidade e ao cárcere deve ser tomada dentro do contexto específico, principalmente, a partir da escuta das mulheres. ${ }^{12}$

\section{ESTÓRIAS}

A seguir, seguem cinco estórias coletadas durante os sete meses de campo da pesquisa Dar à luz na sombra. A partir dessas micronarrativas pretende-se analisar os discursos e as práticas jurídico-penais para trazer à tona valores e subjetividades com marca de gênero que os permeiam.

\section{I Presas no Papel de mãe: disciplinamento da maternidade}

\section{Estória i: Seguro infantil e a carta pro abrigo (São Paulo-SP)}

O dispositivo carcerário presente no dia a dia das pessoas presas se estende ao exercício da maternidade na prisão: a íntima relação de mãe e suas filhas e filhos é disciplinada e conformada dentro da lógica e dos valores do cotidiano prisional; de tal forma que a maternidade pode ser considerada um incremento punitivo para a mulher nessa situação. 
O encontro entre maternidade e prisão produz a hipermaternidade, isto é, o exercício da maternidade superdimensionado, na medida em que, geralmente, é a única atividade das mães presas e, ainda, concentrada em um espaço físico controlado e reduzido. Além das consequências nefastas da hipermaternidade, passados em média seis meses ${ }^{13}$ de convívio 24 horas com o bebê, ela dá lugar à hipomaternidade, ou seja, quando a mãe passa a ter contato reduzido ou nulo com suas filhas e filhos. De forma geral, a transição é feita de forma brusca e descuidada, causando forte impacto nas pessoas envolvidas, instituindo o paradoxo da hiper e da hipomaternidade - tema que foi especificamente desenvolvido em outro trabalho (BRAGA; ANGOTTI, 2015).

Um relato colhido na Penitenciária do Butantã em São Paulo, de regime semiaberto, é exemplificativo desses conceitos e da vivência do paradoxo. No dia da visita à unidade, Lucinéia esperava a chegada do oficial de justiça encarregado de levar sua filha. A espera, além de dolorida, era incerta - não que houvesse outras alternativas para Lucinéia, a separação era certa, ainda que sem hora marcada, pois o oficial poderia aparecer a qualquer momento. Havia se passado seis meses (prazo mínimo legal) que mãe e filha estavam presas, e desde então Lucinéia aguardava angustiada o momento em que levariam sua filha: "Todo dia eu acordo com medo de ser o dia de levarem minha filha. Quando chega as 17 horas fico aliviada, terei mais uma noite com ela”.

As coisas da bebê já estavam arrumadas e junto da mala, cuidadosamente organizada, havia uma carta de Lucinéia destinada às cuidadoras do abrigo, na qual ela narrava os hábitos e a personalidade da bebê, com a esperança de que a filha recebesse um tratamento individualizado e que seu choro fosse compreendido pela "saudade que ela pode sentir da mãe”.

O nome pelo qual o espaço materno-infantil é conhecido entre as presas também é indicativo do regime de poder instituído naquele espaço. O nome oficial Casa Mãe é subvertido pelas presas, que denominam o espaço de "seguro infantil". Seguro é o lugar das prisões destinado às pessoas que não podem estar no convívio por correrem risco de morte. Trata-se do lugar com mais violação de direitos nas unidades prisionais: geralmente superlotado, com restrições a acesso ao banho de sol, atividades na prisão e contato com as outras pessoas.

As puérperas na Penitenciária do Butantã, ainda que em regime semiaberto, ficam confinadas no espaço com seus bebês em regime de "24 por 48 [horas]", como relatou Lucinéia, com uma hora de banho de sol por dia. Nesse sentido, Marina, outra presa entrevistada pela equipe, ressaltou: "quando a gente tá na rua tem coisa pra fazer, roupa pra lavar, comida pra fazer. Aqui não tem nada, é 24 horas cuidando do bebê ou vendo coisa inútil na televisão", e completou, ainda, "nesse ambiente a gente é isolada - tô privando meu bebê de muita coisa - ainda bem que tem essa árvore bonita aqui na janela”. Depois de um tempo de conversa retomou o 
isolamento e reforçou sua angústia: "a gente fica aqui sem contato com ninguém parece bicho!".

Ademais, o prédio da Casa Mãe, localizado mais próximo à entrada da penitenciária, fica ao lado da ala das isoladas, e são as mães que distribuem a alimentação para elas: "a única coisa que a gente faz é pagar alimentação para o castigo". Mas a associação do espaço materno com a ala do castigo tem ainda outros sentidos: em ambas as mulheres estão duplamente presas. Nesse caso, a condição materna é um incremento da punição para a mulher presa, que, mesmo em semiliberdade, fica confinada aos pequenos espaços materno-infantis. Essa queixa foi comum a todas as puérperas que ficavam com suas filhas em espaços pequenos e com poucas opções de atividade, como em Minas Gerais, Ceará e Bahia, vivenciando a hipermaternidade que logo daria lugar à hipomaternidade.

\subsection{InSTITUCIONALIZAÇÃo DAS PEQUENAS VIDAS}

Estória 2: A menina Que não Conhecia as estrelas (Salvador-BA)

Até o final da década de 1990 as crianças filhas de mães presas na Penitenciária Feminina de Salvador, uma das unidades do Complexo da Mata Escura, ficavam nas celas com suas mães, vivendo a disciplina e rotina prisional. Irmã Adele e irmã Fátima, que realizavam visitas à penitenciária, incomodadas com a situação, resolveram fundar, em 1999, o Centro Nova Semente (CNS). Segue um trecho da entrevista ${ }^{14}$ na qual irmã Fátima narra o contexto de surgimento do CNS:

a gente estava trabalhando na Feminina e tinha uma menina que era afilhada dela que se chamava Luiza. Luiza ficou cinco anos presa com a mãe, o pai preso, ela nasceu no presídio [...] aquilo foi incomodando a gente, tinha um menino, Rafael, que ficou quatro anos e mais duas meninas, Laura e Júlia, que ficaram três anos. Nasceram lá e ficaram. Então quando nasceram essas que ficaram três anos e Luiza já com cinco, a gente começou a conversar e deu uma luz assim, vamos tirar essas meninas daqui? E aí teve a ideia de comprar ali onde tem a creche - hoje funciona a escola -, comprou a casinha e começamos a trazer as crianças pra cá, e aí foi tomando conta, compramos outro espaço, foi crescendo...

O abrigo, mantido pela Fundação Dom Avelar Brandão Vilela (FDABV), pertencente à Arquidiocese de Salvador, é vizinho ao Complexo da Mata Escura. Sob a coordenação das duas, e sob os cuidados das duas religiosas, funcionárias e voluntárias, vivem trinta filhas e filhos de mães e/ou pais encarcerados. No CNS, as crianças são cuidadas e educadas, podendo visitar as mães e os pais semanalmente, o que contribui para a manutenção do vínculo entre eles. O fato de o CNS localizar-se ao 
lado do complexo facilita a dinâmica da visita. Irmã Adele afirma que, nas visitas às mães, as crianças não passam por revista, mas contam que as primeiras crianças do estabelecimento, instintivamente, iniciavam a revista elas mesmas, por já estarem acostumadas a isso. Segundo irmã Fátima, se não fosse a presença de uma delas para impedir as crianças, imediatamente já "tiravam a roupinha e faziam o procedimento da revista”.

Na mesma entrevista, irmã Adele narra a estória de Luiza, personagem apresentada acima, nascida na prisão, de mãe e pai presos. Por volta dos 4 anos, ao deixar a prisão uma noite, de carro, na companhia das religiosas, ela se espanta ao olhar para o céu. Apesar da idade, Luiza era uma menina que não conhecia as estrelas, recolhida na cela todo dia às 17 horas - horário da "tranca" na prisão -, não conhecia o céu à noite, assim como não conhecia cachorro, árvore, carro, homem, rua, e tantas coisas do mundo.

Em 2009, a Lei de Execuções Penais foi alterada pela Lei n. 11.942, garantindo que as penitenciárias destinadas às mulheres serão dotadas de seção para gestante e parturiente, e de creche para abrigar crianças maiores de 6 meses e menores de 7 anos. Mas como uma criança de 7 anos pode viver na prisão, e ainda mais em uma prisão brasileira, internacionalmente reconhecidas por sua violência institucional? Viver na prisão limita o mundo. Uma criança na prisão tem não só seus estímulos drasticamente limitados, como também sua vida atravessada pelo dispositivo carcerário. $\mathrm{O}$ mundo que lhe recebe é um mundo de regras, violências, limites, trancas.

Logo, para minimizar o impacto da prisão nas crianças, a institucionalização das pequenas vidas, é preciso pensar em creches e escola sempre fora da instituição prisional e ligadas à rede municipal e estadual de ensino. Longe de o arquipélago carcerário (FOUCAULT, 2002) passar a abarcar também berçário e creches - além das prisões, fundações e manicômios -, propõe-se a aplicação do princípio da incompletude institucional, que norteia no Brasil as políticas da infância e juventude, no sentido de que elas sejam desenvolvidas em conjunto por instituições estatais de diversas áreas e esferas (federal, estadual e municipal), assim como por organizações da sociedade civil.

A observação desse princípio pode funcionar como uma resistência à instituição total, contra a totalização das instituições e a minimização das vidas institucionalizadas. As recentes reconfigurações do ensino e da saúde no sistema prisional brasileiro apontam para esse caminho, ao deslocar competências das secretarias de administração penitenciária para secretarias próprias. Essa mudança reposiciona a prisão e as pessoas presas como participantes da sociedade - uma escola dentro da prisão é mais uma escola da rede pública, um ambulatório na prisão é uma unidade básica de saúde do município, além de permitir que outras lógicas concorram com o paradigma do controle e da segurança que pauta as relações e o funcionamento do espaço prisional. 


\subsection{DisCRiCIONARIEDADE NO SISTEMA}

Estória 3: Dormir no berço: dentro e fora da lei (Ceará x Minas Gerais) Em pesquisa anterior, discutiu-se como a discricionariedade, pessoalidade e falta de transparência são características comuns às administrações das prisões no Brasil (BRAGA, 2013, p. 63). Os objetivos e padrões de procedimento são (re)produzidos de forma autônoma pelas unidades prisionais, levando ao que Rosa Fisher (1989, p. 80) denominou "gerenciamento do cotidiano prisional" - um conjunto de práticas formais e informais, capazes de garantir o bom funcionamento do estabelecimento prisional, cuja autonomia é reforçada pela falta de transparência dessas gestões.

Se o cotidiano prisional brasileiro, de forma geral, não é fruto de políticas pensadas e articuladas, mas resultado de configurações locais (arranjos de poder na prisão, perfil da direção e população prisional, vontade dos gestores), no caso do encarceramento feminino o gerencialismo ganha uma dimensão ainda maior. Historicamente as mulheres não foram objeto - e tampouco sujeitas - das políticas penitenciárias, o planejamento e a execução das poucas políticas efetivas nos cárceres brasileiros estavam até o século passado centralizados na figura do preso homem. E homem aqui faz referência não só a pessoa nascida de sexo masculino, mas também cisgênera e heterossexual.

$\mathrm{Na}$ presente pesquisa ficaram evidenciadas diferenças em termos de procedimentos, deveres e direitos, que variam de um estabelecimento para outro, bem como o personalismo na gestão prisional, presente nas falas das diretoras dos estabelecimentos visitados ao se referirem às unidades que dirigem e às pessoas sob sua direção fazendo uso do pronome possessivo: "minha prisão”, “minhas agentes”, "minhas presas”...

Tal discricionariedade precariza a garantia de direitos no espaço prisional. O exercício da maternidade se inscreve no regime disciplinar e, portanto, é atravessado por normas e sanções. Quanto mais discricionárias e pessoais forem as regulamentações, maior a insegurança física, psíquica e jurídica dessas mulheres, na medida em que o modo de ser presa e ser mãe é determinado pela autoridade local, que dita a lei na unidade.

Uma das constatações da pesquisa foi a falta de uniformização das regras dos cuidados materno-infantis. Por exemplo, a definição de onde deve dormir o bebê é situacional: no Ceará, como a unidade materno-infantil não tem berço, os bebês dormem na cama com a mãe. Já em Minas Gerais, onde todos têm berço, a mãe é obrigada a colocar o bebê no berço para dormir, sob pena de que sua conduta seja considerada falta disciplinar e sob ameaça constante de ser separada do filho ou filha caso descumpra as regras mineiras de como ser mãe. O mesmo ocorre em relação às regras de alimentação. Há unidades em que a mãe é obrigada a dar exclusivamente leite materno até os 6 meses de idade; já em outras, ela deve instituir outros alimentos a partir de 4 meses. Mesmo dentro de um mesmo estado, encontramos discrepâncias entre as 
condições de encarceramento e o cuidado materno-infantil, visíveis principalmente no contraste entre a realidade das mulheres em Cadeias Públicas e em Penitenciárias Femininas, como no caso de São Paulo.

Além de ferir a autonomia da mulher presa, desrespeitando os desejos, crenças e valores que conformariam seu modo próprio de ser mãe, as normas e sanções do cárcere instituem um regime de medo constante, já que qualquer passo dado fora do estabelecido pode levar à separação da criança e a "expulsão" do espaço materno-infantil. Ademais, o desrespeito às regras instituídas ocasiona sanções disciplinares que acabam por envolver as crianças (já que elas estão todo o tempo sob responsabilidade da mãe), como no caso da "tranca", na qual mãe e bebê ficam juntos na cela, em regime de isolamento.

\subsection{Criminosa e Mãe: DUas Capturas}

Estória 4: O INFERNo da GRÁvida E A ASCENSÃo DA PUÉrPERA NO ESPAÇO prisional (Rio de Janeiro e Paraná)

Conforme problematizado anteriormente, a mãe e a criminosa ocupam espectros opostos no rol de papéis designados às mulheres na nossa sociedade. Essa chave interpretativa pode explicar muitos discursos e práticas construídos em torno da mãe criminosa, como os presentes na narrativa que se segue.

O Rio de Janeiro e o Paraná são estados que investiram na construção das unidades materno-infantis. A Unidade Materno Infantil (UMI) do Complexo Penitenciário de Gericinó, em Bangu, foi a primeira creche penitenciária do Brasil, fundada em 1966. Hoje tem autonomia administrativa (com recursos e direções próprias) e é vinculada à coordenadoria de saúde da administração penitenciária. A UMI conta com boa estrutura física e de recursos humanos, além de haver um fluxo entre a unidade e a Justiça da Infância e Juventude. Nela as mulheres ficam soltas de dia, em um terreno com pátio, área verde e uma série de atividades laborais e recreativas. Justo ao lado da UMI, está a Talavera Bruce, também a penitenciária mais antiga do Brasil, ${ }^{15}$ que concentra as grávidas presas no Complexo de Gericinó. A “ala das gestantes” é composta por duas grandes celas, e nelas há apenas beliches, que ocupam o espaço de ponta a ponta. Não há qualquer tipo de cuidado ou tratamento específico que atenda à condição de gestante, os acompanhamentos são externos e dependem de disponibilidade de escolta para acontecerem, as mulheres só saem para banho de sol e poucas trabalham.

No Paraná o contraste é ainda mais gritante, na medida em que a mulher gestante, e mesmo puérpera, não ascende a nenhum lugar na prisão por conta de sua situação especial; ao contrário, lhe era destinado um dos lugares mais precários da prisão: a "Galeria A", onde ficavam as mulheres grávidas, e, nos seis meses após darem à luz, seus bebês. O local destinado a gestantes e puérperas era o mais precário da prisão, 
com péssima infraestrutura, um ambiente completamente insalubre, composto por um espaço bem estreito (uma espécie de corredor com quartos), com sete celas com duas camas cada, um banheiro de uso geral e uma lavanderia. No dia em que a equipe de pesquisa esteve presente, as mulheres da "Galeria A" puderam sair para o banho de sol; porém, em conversas informais, as presas denunciaram que elas não saíam das celas fazia mais de quinze dias e que isso só se deu devido à presença das pesquisadoras na unidade prisional.

Já as crianças maiores de 6 meses eram conduzidas para a creche "Cantinho Feliz", onde passavam a dormir sob os cuidados de duas agentes penitenciárias. A creche, ao abrigar filhas e filhos de mães presas de até 6 anos de idade, é experiência inovadora no Brasil, uma vez que as penitenciárias brasileiras que têm alguma estrutura contam somente com berçários. Porém, se as crianças no Paraná contavam com boa sorte, o mesmo não ocorria em relação às suas mães. Esse foi um padrão que se repetiria no decorrer da pesquisa, de valorização do recém-nascido em detrimento da mãe. Essa tendência apareceu nos demais campos e em diversos discursos que se centravam na defesa dos direitos da criança, mas não falavam da mulher presa.

\subsection{VULNERABiLIDAde FEMININA E SISTEMA DE JUSTIÇA CRIMINAL}

Estória 5: O KIT Visita e a presa fácil (SÃo Paulo-SP)

O perfil da população prisional no Brasil é basicamente um: pessoas pobres, pouco escolarizadas e, em sua maioria, negras. As mulheres não diferem desse perfil, ao contrário, são presas ainda mais fáceis do sistema de justiça criminal devido ao papel que ocupam no tráfico de drogas, o crime que mais prende mulheres hoje no Brasil.

De acordo com o último relatório do DEPEN (BRASIL, 2015), 63\% das mulheres encarceradas no Brasil estão detidas por crimes relacionados a drogas. Normalmente, as mulheres ocupam papéis secundários na economia do tráfico, como transporte, vigilância e manutenção de entorpecentes em casa. São atividades que permitem conciliar as atividades domésticas com atividades tidas como criminosas e que, ao mesmo tempo, deixam as mulheres mais expostas às prisões em flagrante, com materialidade comprovada e, portanto, com menos chances frente ao sistema de justiça criminal.

De acordo com a pesquisa de Iara Ilgenfirtz e Bárbara Soares (2002) sobre o perfil das mulheres presas no Rio de Janeiro no fim da década de 1990, 56,1\% delas estavam presas por crimes associados às drogas. No estudo, as autoras mapearam o lugar que essas mulheres ocupavam na "rede do tráfico": em torno de 50\% declararam estar em funções subsidiárias ou subalternas, como "mula” ou "avião" (que transporta a droga), "vapor” (que negocia pequenas quantidades), "assistente/fogueteira” (que controla a presença da polícia); 27\% se definiram como "bucha” (a pessoa que está presente na cena em que são efetuadas as prisões de alguém envolvido) e 10,7\% 
como cúmplices. Poucas se identificaram como "vendedoras" e apenas uma pequena parte se intitulou como "abastecedora/distribuidora", "traficante", "caixa/contabilidade", "gerente” e "dona de boca”, papéis principais.

Além disso, muitas dessas mulheres são presas justamente ao tentar ingressar com drogas nas prisões masculinas, com o intuito de levá-las aos seus companheiros, filhos e parentes em geral. Essa conduta, além de ser uma causa de aumento de pena do crime de tráfico (art. 40, III, da Lei n. 11.343/06), faz com que a mulher seja levada da unidade visitada diretamente para a prisão, em flagrante.

Visando integrar os pressupostos críticos com uma atuação clínica (voltada para a pessoa), Eugênio Raul Zaffaroni propôs a ideia de clínica da vulnerabilidade 16 enquanto "um saber que permita ajudar as pessoas criminalizadas a reduzir seus níveis de vulnerabilidade" (1998, p. 26) ou "uma técnica tendente a ensinar ao homem a não oferecer a face à bofetada do sistema penal" (1990, p. 64).

Em oposição ao conceito de vulnerabilidade, propõe-se o conceito de sofisticação elaborado por Turk (1969). Para o sociólogo americano, a sofisticação constitui a capacidade de conhecer a conduta dos atores do sistema de controle e manipular a própria conduta a partir desse conhecimento, de forma a dificultar a criminalização. Sujeitos não sofisticados são menos hábeis em avaliar os pontos fortes e fracos de sua posição em relação às autoridades e, consequentemente, têm menos capacidade para evitar a guerra aberta com elas.

A estória ouvida na Cadeia Feminina de Franca, no estado de São Paulo, ilustra bem a falta de sofisticação dessas mulheres ao desafiar a lei criminal. Bárbara, mãe de um bebê de 4 meses, fora visitar o companheiro preso no Centro de Detenção Provisória (CDP) de Franca, porém não passou da porta de entrada, pois, ao passar pelo detector de metais, este foi acionado, o que a levou a ser revistada. Na revista, foram encontradas nas suas cavidades interiores uma trouxinha de maconha e uma "pomada para relações sexuais". A entrada com a pomada nas unidades prisionais, ainda que não permitida, não configuraria crime, e foi justamente o lacre da embalagem que levou à droga. Logo, lhe foi perguntado por que ela não entrara um dia com a pomada e outro com a maconha, e Bárbara respondeu que "Aí não tem graça, o que é bom é os dois juntos!”.

Ainda que possa ser compreensível a ideia de Bárbara em relação ao "kit visita", como entender que ela, mesmo sabendo que estava ingressando em uma unidade prisional com detector de metais, não tomou o simples cuidado de tirar o lacre? Ou então por que não pensou em levar a droga e a pomada em dias diferentes? Essa estória demonstra, de acordo com a imagem trazida por Zaffaroni, como essas mulheres "dão a cara para o sistema de justiça criminal bater”.

Nesse sentido, duas estratégias se apresentam como complementares para a não criminalização dessas mulheres. No plano macrossociológico, lutando pela modificação da lei e da política criminal com o fim de substituir a resposta penal, e na perspectiva 
clínica, microssociológica, fortalecendo as pessoas perante o sistema seletivo e violento, de modo que elas não sejam pegas facilmente pelas teias criminais.

\section{CONCLUSÕES}

As figuras da mãe e da criminosa ocupam polos opostos nas representações do gênero feminino. Enquanto a maternidade atende ao tradicional papel social da mulher, o envolvimento com crime é atestado de desvio do feminino. As mães acusadas e condenadas pelo sistema de justiça criminal vivem essa ambiguidade, encarnando a norma e o desvio, desafiando a lógica binária da racionalidade jurídico-penal. Nesse cenário, a maternidade encarcerada é um dispositivo de normalização da mulher tida como desviante, em busca de uma subjetividade cada vez menos criminosa e cada vez mais maternal.

As estórias aqui narradas apontam para a complexidade que envolve a temática da maternidade e prisão. A partir da "Estória 1: seguro infantil e a carta pro abrigo", discutiu-se como o disciplinamento da maternidade e a ameaça da separação abrupta entre mãe e criança produz maternidades superdimensionadas (hipermaternidade) que serão interrompidas abruptamente (hipomaternidade). $\mathrm{Na}$ "Estória 2: a menina que não conhecia as estrelas", tratou-se do violento impacto que a prisão pode ter nas crianças ao restringir seu mundo às grades. Já a "Estória 3: dormir no berço: dentro e fora da lei" contribuiu com o debate acerca da discricionariedade da administração prisional e suas consequências para o exercício da maternidade. A "Estória 4: o inferno da grávida e a ascensão da puérpera no espaço prisional” ilustrou a supervalorização dos direitos da criança em detrimento dos direitos da mulher. Ao final, com a "Estória 5: o kit visita e a presa fácil", destacou-se a vulnerabilidade da mulher perante o sistema de justiça criminal e a urgência na mudança de política criminal de encarceramento de mulheres.

Entre a soberania da lei e o chão da prisão cabe uma série de problematizações sobre em que medida os avanços legais refletiram em ganhos concretos para as mulheres processadas e condenadas no Brasil. Como se discutiu anteriormente, quando há uma política específica para a gestante ou puérpera, ela só atinge parte das mulheres, principalmente as que estão nas unidades perto das capitais. Depois, mesmo quando as atingem, a garantia de direitos por parte do Estado gera uma punição extra sutil: mais uma esfera da vida disciplinada, mais uma vida normalizada, micropoderes que conformam as estórias que se seguirão. E, por último, a defesa de mais direitos pode gerar o efeito colateral de reforçar a escolha pelo encarceramento.

A defesa de melhores prisões tem o efeito perverso de legitimar maternidades encarceradas. Sob esse argumento, nossas juízas e juízes têm preferido manter mulheres e crianças na cadeia, vigiadas, controladas. Uma melhor possibilidade de exercício da maternidade ocorrerá sempre fora da prisão; se a legislação fosse cumprida, 
tanto em relação à excepcionalidade da prisão preventiva como no tangente à aplicação da prisão domiciliar, grande parte dos problemas que afetam a mulher no ambiente prisional estariam minimizados. A escolha da prisão como resposta quase unívoca do sistema, especialmente para o crime de tráfico, cria paradoxos, os quais seriam evitados caso a gestante ou mãe não estivesse presa.

Logo, a defesa da melhora da situação das mulheres e crianças que vivem nas prisões brasileiras não pode vir dissociada do questionamento mais amplo dos lugares da prisão e dos gêneros na sociedade. Dentre futuras pautas necessárias ao desenvolvimento do debate, duas se mostram urgentes no sentido de desafiar o poder punitivo em relação à mulher encarcerada. Primeiro, discutir o exercício da maternidade apesar da prisão, e nunca na prisão, criando estratégias que desloquem a centralidade da prisão como solução de política criminal. Segundo, com pesquisas que problematizem as associações do feminino com o cuidado. Por que não discutir paternidade e cárcere? Aplicar prisão domiciliar para os homens cuidadores? Creche para unidades masculinas? Ampliação da licença paternidade?

Sem essas reflexões, corre-se o risco de naturalizar a prisão como solução de política criminal e o cuidado materno como exclusivamente responsável e essencial à vida das crianças. Conforme advertiu Smart (1989, p. 3), "o risco é [de que] o discurso jurídico se torne, frente às demandas feministas, mais uma arma contra a mulher do que a favor do feminismo".

Uma terceira pauta - caríssima ao debate de gênero e direito - estaria em discutir formas, meios e palavras utilizados na construção de subjetividades não hegemônicas pelo sistema de justiça e os efeitos do reconhecimento desses novos sujeitos de direito, abrangendo as novas demandas do movimento feminista e LGBT. A problemática final que encerra este artigo é que, ao mesmo tempo que a conquista de direitos aumenta a visibilidade e as políticas de gênero no sistema penal, o sistema de justiça captura essas novas subjetividades pela ação do poder, que vigia, fixa, define e regula:

[...] the rights are no basic rights but formal rights and conformity to specification is a prerequisite for exercising such rights. More rights come at cost of the potential for greater surveillance and greater conformity and the claim for new rights brings about the possibility of new forms of regulation. ${ }^{17}$ (SMART, 1989, p. 162).

Por isso, compartilha-se da ideia de Carol Smart que, inspirada na perspectiva foucaultiana de positividade do poder, propõe que o poder de direito está principalmente em definir eventos e recusar discursos alternativos. Logo, o poder do feminismo - e, nesse sentido, uma resistência, um contrapoder -, mais do que pedir mudanças legislativas, está em desafiar definições, construindo uma realidade alternativa à manifesta no discurso jurídico (SMART, 1989, p. 160). 
A proposta de criminologia feminista, que começa a se delinear no presente trabalho, é de se debruçar sobre os discursos e as práticas jurídico-penais para trazer à tona valores e subjetividades com marca de gênero que os permeiam. Problematizar como o sistema de justiça criminal produz, organiza e fixa valores de gênero, além das consequentes desigualdades sutis e silenciadas advindas desse marco.

Nesse sentido, apostou-se nas narrativas do cárcere como formas de enfrentar o seu silenciamento. No fim da caixa de pandora, saem crianças e mães enlutadas. Daí a importância de etnografias, histórias de vida, narrativas como processo de resistência à mortificação material e simbólica dessas vidas condenadas. Cabe ressaltar que se pretendeu o cuidado ético de não falar em nome dessas mulheres (por elas), ao contrário, propõe-se um caminho na contramão: que essas mulheres falem por nós através de suas histórias, nos guiem na reflexão e mostrem caminhos para enfrentar a questão. A academia está longe de sentir na pele o drama da prisão, mas não pode se eximir de retratá-lo como produção concreta da (in)justiça, desde um possível lugar de encontro.

NOTAS

1 De acordo com dados do relatório do DEPEN realizado com base nos dados do Levantamento Nacional de Informações Penitenciárias (Infopen) de dezembro de 2011 (BRASIL, 2014).

2 Dados disponíveis em: <http://www.prisonstudies.org/country/brazil>. Acesso em: mar. 2014.

3 IBGE. Censo 2010. Disponível em: <http://www.ibge.gov.br/home/estatistica/populacao/censo2010/ tabelas_pdf/Brasil_tab_1_4.pdf>. Acesso em: 17 jul. 2015.

4 De acordo com os últimos dados coletados pelo Infopen.

5 “A fim de reivindicar direitos, o indivíduo deve se enquadrar em categorias específicas” (tradução nossa).

6 "não podemos prever o resultado de qualquer reforma do direito individual. Na verdade, o principal dilema para qualquer engajamento feminista com a lei é a certeza de que, uma vez aprovada, a legislação está nas mãos de indivíduos e agências muito distantes dos valores e políticas do movimento de mulheres" (tradução nossa).

7 “[...] a lei pode ter efeitos muito diferentes dependendo de quem é o sujeito da lei” (tradução nossa).

8 A equipe de pesquisa foi composta por Bruna Angotti na vice-coordenação; Carolina Costa, Davílis Maza, Fernanda Ozilak, Naila Chaves Franklin e Paula Pereira Gonçalves Alves como assistentes de pesquisa. 
9 Aqui cabe ressaltar que as estratégias e concepções dos movimentos feministas em relação ao sistema de justiça criminal são diversas, assim como o são os feminismos. Neste trabalho, adotamos a perspectiva de Carol Smart de desconfiança em relação ao poder do direito, com a proposição de caminhos alternativos para a luta feminista.

10 As reflexões aqui apresentadas são fruto do campo da pesquisa e algumas delas estão no relatório final da pesquisa (BRASIL, 2015).

11 "Essa racionalidade baseia-se no pressuposto de que a mulher que aceita seu papel tradicional, que é passivo, gentil e cuidadoso, é também não criminosa” (tradução nossa).

12 Esse insight veio logo no início da pesquisa, na realização do grupo focal na Cadeia Feminina de Franca (SP). O fato de as próprias presas debaterem coletivamente os temas da pesquisa e discordarem em muitos pontos permitiu verificar-se que não há consenso do que fazer em termos de maternidade e prisão.

13 De acordo com a Lei de Execução Penal, seis meses é o prazo mínimo estabelecido em lei para que as mulheres presas possam permanecer com seus bebês.

14 Realizada no Centro Nova Semente no Complexo da Mata Escura em Salvador, em dezembro de 2012.

15 Para uma história do encarceramento feminino do Brasil ver Angotti (2012).

16 Zaffaroni escolhe mudar a denominação "criminologia clínica” para "clínica da vulnerabilidade" a fim de, justamente, romper com a associação dessa criminologia com aquela outra formulada pela escola positivista italiana.

17 “[...] os direitos não são direitos básicos, mas direitos formais e conformidade à especificação é um prérequisito para o exercício desses direitos. Mais direitos vêm ao custo do potencial aumento da vigilância e conformidade e a demanda por novos direitos traz a possibilidade de novas formas de regulação" (tradução nossa).

\section{REFERÊNCIAS BIBLIOGRÁFICAS}

ANGOTTI, Bruna. Entre as leis da ciência, do Estado e de Deus: o surgimento dos presídios femininos no Brasil. São Paulo: IBCCRIM, 2012.

BRAGA, Ana Gabriela Mendes. Preso pelo Estado e vigiado pelo crime: as leis do cárcere e a construção da identidade na prisão. Rio de Janeiro: Lumen Juris, 2013.

; ANGOTTI, Bruna. O excesso disciplinar: da hipermaternidade à hipomaternidade no cárcere feminino brasileiro. 2015. No prelo.

BRASIL. Ministério da Justiça. Departamento Penitenciario Nacional (DEPEN). Sistema Integrado de Informacoes Penitenciarias (Infopen). Mulheres presas - dados gerais. Brasília, 2014. Disponível em: $<$ http://www.justica.gov.br/noticias/mj-divulgara-novo-relatorio-do-infopen-nesta-terca-feira/relatoriodepen-versao-web.pdf>. Acesso em: 15 nov. 2015.

Ministério da Justiça. Secretaria de Assuntos Legislativos. Dar à luz na sombra: condições atuais e possibilidades futuras para o exercício da maternidade por mulheres em situação de prisão. Brasília: Ministério da Justiça; Ipea, 2015. Disponível em: <http://participacao.mj.gov.br/pensandoodireito/wpcontent/uploads/2015/03/51-Dar-a-luz-na-sombra.pdf>. Acesso em: 15 nov. 2015.

BUTLER, Judith. O parentesco é sempre tido como heterossexual? Cadernos Pagu, Unicamp, v. 21, p. 219-260, 2003. CERNEKA, Heidi Ann. Regras de Bangkok: está na hora de fazê-las valer! Boletim IBCCRIM, São Paulo, ano 20, n. 232, p. 18-19, ago. 2012.

DELEUZE, Gilles. ¿Que és un dispositivo? In: Michel Foucault, filósofo. Barcelona: Gedisa, 1990. p. 155-161. DINIZ, Debora. Perspectivas e articulações de uma pesquisa feminista. In: STEVENS, Cristina; OLIVEIRA, Susane Rodrigues de; ZANELLO, Valeska (Orgs.). Estudos feministas e de gênero: articulações e perspectivas. Florianópolis: Ed. Mulheres, 2014. p. 11-21. 
FISCHER, Rosa Maria. Poder e cultura em organizações penitenciárias. 1989. Tese (Livre-docência) - Faculdade de Economia e Administração, Universidade de São Paulo, São Paulo, 1989.

FOUCAULT, Michel. Sobre a história da sexualidade. In: Microfísica do poder. Rio de Janeiro: Graal, 2000. p. 243-227.

Vigiar e punir: história da violência nas prisões. Petrópolis: Vozes, 2002.

GUILLIGAN, Carol. Teoria psicológica e desenvolvimento da mulher. Lisboa: Fundação Calouste Gulbenkian, 1997. ILGENFRITZ, Iara; SOARES, Bárbara Musumeci. Prisioneiras: vida e violência atrás das grades. Rio de Janeiro: Garamond, 2002.

LOMBroso, Cesare; FERRERO, Guglielmo. Criminal Woman, the Prostitute, and the Normal Woman. Translated by Nicole Hahn Rafter and Mary Gibson. Durham: Duke University Press, 2004.

QUINTINO, Silmara Aparecida. Creche na Prisão Feminina do Paraná: humanização da pena ou intensificação do controle social do Estado? 2005. Dissertação (Mestrado em Sociologia) - Universidade Federal do Paraná, 2005. RIFIOTIS, Theophilos. Direitos humanos: sujeito de direitos e direitos dos sujeitos. In: SILVEIRA, Rosa Maria G. et al. Educação em direitos humanos: fundamentos teórico-metodológicos. João Pessoa: Editora Universitária, 2007. p. 231-244.

ROSA, João Guimarães. As margens da alegria. In: Primeiras estórias. Rio de Janeiro: Nova Fronteira, 2001. p. 49-45.

SMART, Carol. Woman, crime and criminology: a feminist critique. London: Routledge and Kegan Paul, 1976. Feminism and the power of law. London: Routledge, 1989.

TURK, Austin. Criminality and legal order. Chicago: Rand McNally, 1969.

ZAFFARONI, Eugênio Raul. A criminologia como instrumento de intervenção na realidade. Revista da Escola do Serviço Penitenciário do Rio Grande do Sul, Porto Alegre, v. 1, n. 4, p. 51-68, jul.-set. 1990. . Criminología: aproximación desde un margen. Santa Fé de Bogotá: Temis, 1998.

\section{Ana Gabriela Mendes Braga}

Franca - SP - Brasil anagabrielamblagmail.com
Doutora em CRIMINologia PELA Universidade de São Paulo (USP) com estágIo doutoral NA Universitat DE BARCELONA (UB).

Professora da Universidade Estadual Paulista (UNESP), CAMPUS DE Franca. 
